\title{
A role for glutamate in subjective response to smoking and its action on inhibitory control
}

\author{
J. Nesic • T. Duka • J. M. Rusted • A. Jackson
}

Received: 25 August 2010 / Accepted: 17 January 2011 /Published online: 9 February 2011

(C) The Author(s) 2011. This article is published with open access at Springerlink.com

\begin{abstract}
Rationale Our previous study using memantine in smokers suggests that there may be a differential role for $\mathrm{N}$-methylD-aspartate (NMDA) receptors in the subjective and cognitive effects of smoking.

Objectives This study was designed to investigate if Dcycloserine (DCS) would modulate the subjective and cognitive effects of limited smoking.

Methods Forty-eight habitual smokers abstinent for a minimum of $2 \mathrm{~h}$ were randomly allocated to receive either placebo or $50 \mathrm{mg}$ DCS (double-blind) and were subsequently required either to smoke half of one cigarette or to remain abstinent. Subjective and physiological effects of DCS were measured at baseline, $90 \mathrm{~min}$ postcapsule, and again after the partial-smoking manipulation, while the effects on sustained attention (rapid visual information processing test-RVIP) and cognitive flexibility (intraextra dimensional set-shift test-IED) were evaluated only after the partial-smoking manipulation.

Results DCS alone did not produce significant subjective effects other than an increase in ratings of "Stimulated". In combination with partial smoking, however, DCS blocked the smoking-induced increase in "Stimulated" and the
\end{abstract}

J. Nesic and A. Jackson contributed equally to this work.

J. Nesic $\cdot$ A. Jackson $(\bowtie)$

Department of Pharmacology and Therapeutics, School of

Pharmacy and Biomolecular Sciences, University of Brighton,

Moulsecoomb,

Brighton BN2 4GJ, UK

e-mail: aj4@bton.ac.uk

T. Duka · J. M. Rusted

Department of Psychology, School of Life Sciences,

University of Sussex,

Falmer,

Brighton BN1 9QG, UK decrease in "Relaxed" ratings. Furthermore, in combination with smoking, DCS reduced the number of false alarms during the RVIP test (an index of inhibitory control) and produced a small increase in diastolic blood pressure. DCS failed to modulate IED performance.

Conclusions These findings provide further evidence of a role for glutamate release in the subjective effects of smoking but not the effects on attention and cognitive flexibility. Furthermore, our results indicate that glutamate release may also be involved in the effect of smoking on inhibitory control.

Keywords Smoking $\cdot$ D-Cycloserine $\cdot$ Glutamate . Subjective $\cdot$ Cognition $\cdot$ Inhibitory control

\section{Introduction}

Nicotine is known to produce a variety of rewarding subjective and cognitive effects (Stolerman and Jarvis 1995; Levin et al. 2006). In humans, some of the measurable subjective effects of nicotine include an increase in the feelings of "buzzed," "dizzy," and "stimulated" (Perkins et al. 1999), while the positive cognitive effects include improvements in attention (Wesnes and Warburton 1984) and memory (Rusted et al. 1998; 2005). The neurobiological mechanisms underlying these actions of nicotine are complex, involving not only the direct action of nicotine at receptors for acetylcholine but also changes in the release of other neurotransmitters, such as dopamine and glutamate (Watkins et al. 2000). Neurochemical studies have demonstrated that, at concentrations achieved during smoking, nicotine can enhance the release and function of glutamate, through an action at presynaptic receptors (e.g., McGehee et al. 1995). Enhanced release can occur in 
several areas of the brain, including in the ventral tegmental area and the nucleus accumbens (Schilstrom et al. 1998, 2000; Fu et al. 2000; Reid et al. 2000, Mansvelder and McGehee 2000; Fagen et al. 2003), the prefrontal cortex (Toth et al. 1993; Gioanni et al. 1999), and the hippocampus (Gray et al. 1996; Radcliffe et al. 1999).

Evidence from behavioral models also indicates a role for glutamate in the neurobiological mechanisms underlying the actions of nicotine. In rodents, it has been reported that antagonists acting at $N$-methyl-D-aspartate (NMDA) receptor sites can attenuate nicotine self-administration, the nicotine discriminative stimulus, and nicotine-enhanced brain reward function (Glick et al. 2001; Blokhina et al. 2005; Zakharova et al. 2005; but see also Wright et al. 2006; Kenny et al. 2009). Receptor sites other than NMDA may also be involved in these actions of nicotine as the metabotropic GluR5 antagonist 2-methyl-6-(phenylethynyl)-pyridine (MPEP) has also been reported to be effective in models of self-administration (Paterson et al. 2003; Paterson and Markou 2005). In studies of the cognitive effects of nicotine, interactions with glutamatergic ligands have been reported in tests of working memory and visual signal detection (Levin et al. 1998; May-Simera and Levin 2003; Rezvani and Levin 2003), and Quarta et al. (2007) have recently reported that the competitive NMDA receptor antagonist (+)3-(2-carboxypiperazin-4-propyl)-1propenyl-1-phosphonic acid (CPP) attenuated the ability of nicotine to improve response accuracy in a five-choice serial reaction time task. In a spatial navigation task performed by aged rats, CPP also blocked a beneficial effect of nicotine on acquisition, while D-cycloserine enhanced the effect of a subthreshold dose of nicotine (Riekkinen and Riekkinen 1997). In mice, Ciamei et al. (2001) showed that the NMDA antagonist dizocilpine could block the positive effects of nicotine on memory consolidation, at a dose not producing impairment per se.

Few studies have examined the involvement of glutamate in the actions of nicotine or smoking in humans. Knott et al. (2006) found some evidence for nicotine-glutamate interactions on both subjective and EEG measures in volunteers given nicotine gum, although effects varied with smoking status. Recently, we demonstrated the involvement of the NMDA receptor in the effects of smoking (Jackson et al. 2009). In this study, the NMDA antagonist memantine was effective in blocking the subjective but not the cognitive enhancing effects of smoking. In contrast, a low dose $(10 \mathrm{mg})$ of the nicotinic-receptor antagonist mecamylamine reduced the smoking-induced improvement in attentional performance only. These results suggested that there is a dissociation in the role of glutamate in the subjective and cognitive effects of smoking. It has been argued however that although memantine acts primarily at the ion channel of the NMDA receptor, during the physiological release of glutamate, it dissociates rapidly from the channel, to allow a normal receptor response to glutamate (Parsons et al. 1999; 2007). As this putative special action of memantine complicates the interpretation of results aimed at clarifying the role of glutamate, we carried out a further investigation, using a different modulator of NMDA receptor function.

Endogenous glycine acts as a "co-agonist" at a distinct site on the NMDA receptor, known as the GlycineB site, and in doing so enhances the action of glutamate. Although the GlycineB site was once thought to be saturated in vivo, there is now consensus that it is not (Danysz and Parsons 1998; Haradahira et al. 2003; Millan 2005), therefore offering the possibility that ligands acting at this site can modulate the action of glutamate at the NMDA receptor. D-Cycloserine (DCS) is a partial agonist that acts at the GlycineB site of the NMDA receptor (Hood et al. 1989; Priestley et al. 1995) and is believed to be selective (Millan 2005). As a partial agonist, it acts firstly to bind to the site and prevent the action of glycine (i.e., as an antagonist), but with increasing concentration of the drug, efficacy increases (i.e., an agonist action); at high concentrations, the efficacy of DCS appears to diminish (Priestley et al. 1995). In theory then, if glutamate action at NMDA receptors is involved in the actions of smoking, a single low dose of DCS would reduce effects mediated by a high level of endogenous stimulation at NMDA receptors (via an antagonist action at the GlycineB site) but potentiate its effects where there is a lower level of endogenous activity (via an agonist action at the GlycineB site). We therefore carried out a study to investigate the effects of DCS on the cognitive and subjective effects of smoking. We used $50 \mathrm{mg}$ DCS as a low dose that has previously been reported to be active in human studies (Ressler et al. 2004; Bailey et al. 2007). In addition, to allow the possible bidirectional modulation of smoking effects by DCS, we asked participants to smoke just a portion of a cigarette (partial smoking) following a period of abstinence. We employed a similar battery of tests to those used in our previous study. This included the rapid visual information processing task (RVIP) as a measure of sustained attention, known to be sensitive to the effects of smoking (Wesnes and Warburton 1984) and visual analog scales to measure nicotine- and NMDA-antagonist-related subjective effects (Jackson et al. 2009). In addition, we extended the battery to include a test of attentional set-shifting for two reasons: firstly, we have found in our own studies that smoking can impair performance on the task (Nesic et al. 2011), and secondly, evidence exists to show that glutamatergic ligands, including DCS, can modulate cognitive flexibility in humans (Krystal et al. 1998; Heresco-Levy et al. 2002). To our knowledge, this was 
the first study to examine the acute effects of DCS in a population of smokers (previously published in abstract form, Nesic et al. 2008).

\section{Method}

\section{Participants}

Forty-eight participants (24 male, 24 female) aged 18-34 (mean 22.7 \pm SEM 0.6) who smoked 5-20 cigarettes per day (mean $12.5 \pm$ SEM 0.7 ) were recruited from the staff and students at the Universities of Brighton and Sussex and gave written informed consent to take part in the study. Individuals who habitually smoked more than 20 cigarettes per day were not excluded, but none came forward to take part in the study. The participants were fluent in English, generally healthy, with no previous history of psychiatric illness or substance abuse (verified by a medical check), and were not taking any medication at the time of testing. The volunteers were dependent smokers, as indicated by the Fagerström Tolerance Questionnaire (FTQ; Fagerström 1978) score of 5 or above (5-9, mean 5.8 \pm SEM 0.2).

Volunteers were instructed to refrain from smoking for at least $2 \mathrm{~h}$ prior to the testing session (actual range $2-34 \mathrm{~h}$, mean $8.6 \pm$ SEM $0.9 \mathrm{~h}$ ) and were told that compliance would be verified by administration of a Smokerlyzer test. They were asked to avoid using illicit drugs for at least 1 week, sleeping pills and other sedatives for $48 \mathrm{~h}$, and alcohol for $12 \mathrm{~h}$ before the testing session. Volunteers were informed that the purpose of the study was to investigate if D-cycloserine (DCS) is able to modulate the subjective and cognitive effects of smoking. They were told that they would receive a capsule containing either placebo or $50 \mathrm{mg}$ DCS and that they may be asked to smoke a portion of one of their own cigarettes during the testing session. At the start of the testing session volunteers' IQ was assessed using the National Adult Reading Test (NART).

This study was approved by the Research Ethics Committees of the University of Sussex and the University of Brighton. Participants received $£ 25$ at the end of the testing session as compensation for their time.

\section{Experimental design}

Volunteers were randomly allocated to one of the four experimental conditions and tested individually in a between-subjects $2 \times 2$ design, fully balanced for gender, with the between-subjects factors being drug (placebo-PL vs. D-cycloserine-DCS) and the partial-smoking condition (abstinent-NS vs. partial smoking - S). In order to assess temporal changes during the course of the experimental session, "time point" was introduced as a within-subject factor for some of the dependent variables. Dependent variables were subjective effects, craving for cigarettes, and cardiovascular measures (three time points) as well as sustained attentional performance (one time point).

Drug treatments

DCS was obtained from a local pharmacy as generic cycloserine capsules BP (King Pharmaceuticals Ltd, Donegal, Ireland). Drug and placebo (cornstarch) were subsequently prepared in opaque, gelatine-free capsules (Quali- $V^{\circledR}$, Qualicaps) at the School of Pharmacy and Biomolecular Sciences, University of Brighton. A dose of $50 \mathrm{mg}$ DCS was chosen for two reasons: Firstly, this dose has been reported to be active and to have good tolerability in many previous studies (van Berckel et al. 1997; Ressler et al. 2004; Hofmann et al. 2006; Bailey et al. 2007), and secondly, in vitro studies indicate that efficacy is lost at high concentrations (Priestley et al. 1995) and it was unclear at what dose this might occur in vivo.

\section{Demographic questionnaires}

In addition to the FTQ and the questions about the onset and duration of smoking habit, demographic questionnaires included an Alcohol Use Questionnaire (AUQ; Mehrabian and Russell 1978) and the Drug Use Questionnaire (DUQ; Nesic et al. 2011). The AUQ is a selfreport questionnaire that establishes the average weekly alcohol intake and patterns of drinking behavior over a 6-month period. The DUQ is a self-report questionnaire that establishes lifetime as well as frequency of current use of illicit drugs, including amphetamines, cocaine, crack, MDMA, hallucinogens, opiates, ketamine, gammahydroxy-butyrate (liquid ecstasy), alkyl nitrite inhalants (poppers), nitrous oxide (laughing gas), and cannabis. Drugs included in the DUQ are scored as follows: $0=$ never used, $1=$ not used in the last month, $2=$ used once in the last month, $3=$ used $2-5$ times in the last month, $4=$ used 6-10 times in the last month, $5=$ used more than 10 times in the last month (with the exception of cannabis, which is scored as follows: $0=$ never smoked, $1=$ not smoked in the last month, $2=$ smoked once in the last month, $3=$ smoked $\leq$ once a week in the last month, $4=$ smoked several times a week in the last month, and $5=$ smoked every day in the last month). Analysis is performed on each individual item as well as on the total drug use score which is obtained by adding up all the scores for individual drug items. This is an extended version of a previous DUQ developed in our laboratory which has been used for drug screening purposes in a number of studies involving social drinkers (Nesic and Duka 2006; 2008) and smokers (Nesic et al. 2011). 
Subjective measurements

Visual analog scales A list of nicotine-related subjective effects (nicotine-VAS) and a list of NMDA antagonist-related subjective effects (NMDA-VAS) were presented, and volunteers were instructed to answer how much each adjective described how they felt at that moment by placing a mark on the bipolar visual analog scales (VAS-100 mm) with the poles "not at all" on the left and "extremely" on the right. The nicotine-VAS items were "stimulated," "buzzed," "impatient," "alert," "irritable," "jittery," "dizzy," "relaxed," and "hungrier than usual" (Jackson et al. 2009- based on Perkins et al. 1999). The NMDA-VAS items were "lightheaded," "detached," "forgetful," "things seem to be moving in slow motion," and "unreal" (Jackson et al. 2009).

Questionnaire of Smoking Urges The brief version of Questionnaire of Smoking Urges (QSU) consists of 10 questions designed to measure desire to smoke and anticipation of positive outcome (factor 1: positive reinforcement) as well as strong urge to smoke and anticipation of relief of withdrawal (factor 2: negative reinforcement; Cox et al. 2001). The participants were required to rate how much each statement applied to them at that particular moment by writing a mark on a Likert-type seven-point scale, ranging from "strongly disagree" (1) to "strongly agree" (7).

\section{Cognitive assessment}

RVIP A five-minute RVIP test of sustained attention (based on Wesnes and Warburton 1984) was administered using E-Prime 1.1 software and a response box (Psychology Software Tools Inc). Volunteers were required to monitor a continuous stream of digits, presented at a rate of 80 digits per minute, and to press a response button whenever they saw either three consecutive odd or three consecutive even digits. There were eight such target strings of digits in each one-minute block of the 5-min test, making a total of 40 targets. The number of correct targets detections ("hits") was recorded within a 1,500-ms window following the onset of the third digit in the target sequence. The average latency of correct detections and the number of false alarms (responses to nontargets) were also recorded. Due to a technical error, RVIP data were lost for one of the participants in the DCS/S group.

Intra-extra dimensional set-shift test The intra-extra dimensional set-shift test (IED; Cambridge Neuropsychological Test Automated Battery, Cambridge Cognition) is a computerized touch-screen test of rule acquisition and reversal, which begins as a simple visual discrimination task and then gradually increases in the degree of complexity. The display features two stimuli in the form of shapes and/or shapes and lines that appear randomly in two of the four possible locations on the computer screen. Initially, volunteers are required to learn a simple discrimination (i.e., which of the two shapes is correct), then simple reversal (i.e., change of contingencies, where the previously incorrect shape becomes correct), and then to attend to the correct shape even when the stimuli become more complex by the addition of the lines. Subsequently, a new pair of the compound shape-line stimuli appears, and volunteers are required to maintain attention to shapes and to ignore the lines (stage 6-the intradimensional (ID) shift). Finally, in stage 8, another new pair of compound stimuli appears, and volunteers are now required to switch their attention to the previously irrelevant dimension, the lines (the extradimensional (ED) shift). The main outcome measures derived from this test are the number of stages completed (1-9), total number of errors on the test, the number of errors made on each of the nine blocks, and the total number of errors prior to the extradimensional shift block. Additionally two composite outcome measures were analyzed: attentional flexibility (errors in stages $6+8$ ) and reversal learning (errors in stages $2+5+7+9$ ).

An associative verbal memory test was also used in this study; no effects of DCS or partial smoking were observed on performance of this test, and the results are not reported here.

Experimental procedure

Volunteers reported either to the University of Sussex or to the University of Brighton Psychopharmacology Laboratory having been asked to abstain from smoking for at least $2 \mathrm{~h}$. They first completed a Smokerlyzer test measuring exhaled carbon monoxide (CO) levels in order to verify compliance with the abstinence requirement. At the start of the testing session, volunteers performed the NART after which they were given the opportunity to familiarize themselves with the RVIP task (20-40-s practice trial). Following this, they completed Nic-VAS, NMDA-VAS, and QSU scales (2-3 min), and their blood pressure was measured using an automatic monitor (time point: baseline).

Volunteers were then given a capsule which they swallowed with approximately $100-\mathrm{ml}$ water and waited for $90 \mathrm{~min}$, during which they completed the demographic questionnaires. At the end of the waiting period, participants' blood pressure was measured again, and they completed a Smokerlyzer test followed by a test battery consisting of a 30-min memory test, Nic-VAS, NMDAVAS, and QSU (time point: presmoke). After the test 
battery, half of the volunteers were taken to the designated smoking area and asked to smoke one half of one of their own cigarettes, while the other half of the volunteers remained abstinent. The portion of the cigarette to be smoked was determined individually for each participant by asking them to indicate the point on their cigarette up to which they would normally smoke before putting it out, measuring the length of this portion and then marking a line halfway along to ensure that they smoked exactly one half of the amount that they would usually smoke. Upon returning to the testing room, participants completed another Smokerlyzer test followed by a test battery consisting of nicotine-VAS, NMDA-VAS, QSU, RVIP, IED, and a 10-min memory test, after which their blood pressure was measured again (time point: postsmoke). At the end of testing, participants were debriefed about the purpose of the study, were given $£ 25$, and were allowed to leave the laboratory.

\section{Data analyses}

Demographic data, duration of abstinence, baseline breath $\mathrm{CO}$, and NART scores of the four experimental groups were analyzed using univariate analysis of variance (ANOVA) with drug group (PL vs. DCS) and partial-smoking condition (NS vs. S) as between-subjects factors. The effects of the drug alone on subjective measures were evaluated using repeated-measures ANOVA with drug group as the between-subjects factor and time point (baseline vs. presmoking) as the within-subjects factor.

Prior to analyzing the effects of the drug and the partial-smoking manipulation on subjective measures and breath $\mathrm{CO}$ levels, data from the presmoking time point were analyzed using univariate ANOVAs with drug group and partial-smoking condition as between-subjects' factors. Whenever there was a significant interaction of the two factors at this time point, the postsmoking data for that variable were converted into percent of change from the presmoking time point and analyzed using univariate ANOVA with drug and partial-smoking group as between-subjects' factors. If the interaction of the two factors at the presmoking time point was not significant, these variables were evaluated using repeated-measures ANOVA with the drug group and the partial-smoking condition as between-subject factors and time point (prevs. postsmoking) as a within-subject factor. Since the distribution of response latencies on the RVIP usually shows positive skewness, natural log transformation was applied to normalize these data prior to analyses. RVIP data (response latencies, hits, false alarms) as well as IED outcome measures were analyzed using univariate ANOVA, with drug group and partial-smoking condition as between-subject factors.
All significant interactions were explored using appropriate paired and/or unpaired post hoc $t$ tests. We have decided against applying corrections for multiple comparisons as this was a simple $2 \times 2$ design $(2 \times 2 \times 2$ for the subjective effect variables which were measured before and after the drug and/or smoking manipulation), and such corrections are not recommended for exploration of significant interactions which involves five or less planned post hoc comparisons (Roberts and Russo 1999).

All statistical analyses were performed using SPSS 15.0.

\section{Results}

Population characteristics

The four experimental groups were matched with respect to age, NART, and smoking habit as well as alcohol and other drug use $\left(F_{\mathrm{s}}[1,44]<3.60, p \mathrm{~s}>0.06\right)$. Demographic characteristics of the four groups are presented in Table 1. A main effect of drug group was significant for the number of hours since the last cigarette, with volunteers allocated to the DCS group being abstinent for longer than those in the PL group (means $\pm \mathrm{SEM}$ : $\mathrm{PL}=6.7 \pm 1.0 \mathrm{~h}, \mathrm{DCS}=$ $10.5 \pm 1.5 \mathrm{~h} ; F[1,44]=4.62, p<0.05)$. Furthermore, a significant main effect of the smoking group was observed for the baseline breath CO levels, with participants allocated to the nonsmoking condition having higher baseline levels $(F[1,44]=4.79, p<0.05$; Table 2$)$. In order to control for the potentially confounding influence of these differences on the experimental outcome measures, the number of hours since last cigarette was entered as a covariate in all subsequent ANOVAs, while the baseline breath $\mathrm{CO}$ level was entered as an additional covariate only in the analyses of the postsmoking time point measurements. Only results from the ANCOVAs will be reported here.

Physiological effects

Effects of DCS during abstinence (baseline vs. presmoke)

The ANCOVA of breath CO levels during abstinence (baseline vs. presmoking) revealed a main effect of time, with all participants showing a decline in $\mathrm{CO}$ levels across the two time points $(F[1,45]=53.69, p<0.001$; Table 2).

Blood pressure and heart rate remained constant during abstinence (main effects of time: $F_{\mathrm{S}}[1,45]<2.50$, n.s.). DCS did not exert any significant effects on either systolic or diastolic blood pressure (time $\times$ drug interaction: $F_{\mathrm{s}}[1,45]<0.84$, n.s.), although a main effect of drug was found for the diastolic blood pressure $(F[1,45]=9.71$, 
Table 1 Demographic characteristics of the four experimental groups $(\mathrm{DCS}=\mathrm{D}$-cycloserine condition, $\mathrm{PL}=$ placebo condition, $\mathrm{S}=$ partial-smoking condition, NS = nonsmoking condition)

Values represent means $( \pm$ SEM)

\begin{tabular}{lrrrr}
\hline$n=12$ per group (6 male, 6 female) & DCS/NS & \multicolumn{1}{l}{ DCS/S } & PL/NS & \multicolumn{1}{c}{ PL/S } \\
\hline Age (years) & $24.3(1.5)$ & $22.4(1.0)$ & $22.5(1.2)$ & $21.6(0.8)$ \\
NART score & $33.0(2.5)$ & $28.9(1.7)$ & $29.0(2.1)$ & $30.0(1.3)$ \\
Number of cigarettes/day & $12.4(1.7)$ & $11.7(1.4)$ & $12.1(1.1)$ & $13.8(1.8)$ \\
FTQ score & $5.9(0.4)$ & $5.3(0.2)$ & $5.8(0.2)$ & $6.1(0.4)$ \\
Number of years smoking regularly & $8.5(1.7)$ & $6.3(0.9)$ & $6.7(1.0)$ & $5.7(0.9)$ \\
Alcohol use (units/week) & $37.2(6.6)$ & $38.0(7.5)$ & $27.5(3.9)$ & $30.0(4.4)$ \\
Drug use (total DUQ score) & $8.8(1.8)$ & $9.6(1.9)$ & $6.4(1.2)$ & $6.6(1.7)$ \\
\hline
\end{tabular}

$p<0.005$; Table 2). Post hoc independent $t$ tests indicated that the participants in the DCS group had lower diastolic blood pressure than the PL group at baseline as well as at the presmoking measurement point $(t[46]=2.19, p<0.05$ and $t[46]=3.66, p<0.001$, respectively). No other main effects or interactions were observed for the blood pressure and heart rate data $\left(F_{\mathrm{s}}[1,45]<2.85\right.$, n.s. $)$. Blood pressure and heart rate data are presented in Table 2.

\section{Effects of DCS in combination with partial smoking (presmoke vs. postsmoke)}

Repeated ANCOVA of the CO levels before and after the partial-smoking manipulation in the entire experimental sample revealed a significant two-way interaction of partialsmoking condition and time point $(F[1,42]=34.50$, $p<0.001$; Table 2). Post hoc $t$ tests revealed that breath $\mathrm{CO}$ significantly increased in the $\mathrm{S}$ condition $(t[23]=-5.27$, $p<0.001)$ and declined in the NS condition $(t[23]=4.61$, $p<0.001)$. The three-way interaction of drug group, partialsmoking manipulation, and time point was not significant $(F[1,42]=1.80$, n.s. $)$ suggesting that DCS did not alter the amount of smoke inhaled.

A significant three-way interaction for the diastolic blood pressure was revealed in the repeated ANCOVA (time $\times$ drug $\times$ smoking: $F[1,42]=7.56, p<0.01$; Table 2). Post hoc $t$ tests indicated that partial smoking significantly increased diastolic blood pressure only in the DCS group $(t$ $[11]=-3.01, p<0.05)$, while a similar increase was not observed in the PL group $(t[11]=0.82$, n.s. $)$. The main effect of drug was again significant $(F[1,42]=9.51$, $p<0.01$ ), although the DCS group no longer had lower blood pressure than the PL group at the postsmoking measurement (independent $t[41.14]=1.80$, n.s.). Independently of the drug manipulation, partial smoking also induced a significant increase in systolic blood pressure $(t[23]=-2.51, p<0.05)$ which was not seen in the abstinent group $(t[23]=1.288$, n.s.; smoking $\times$ time point interaction: $F[1,42]=9.81, p<0.005$; Table 2). No other main effects or interactions were observed in the analyses of the blood pressure and heart rate $\left(F_{\mathrm{S}}[1,42]<2.65\right.$, n.s. $)$.
Subjective effects

\section{Effects of DCS during abstinence (baseline vs. presmoke)}

Main effects of time point were observed for Nic-VAS ratings "buzzed," “impatient," "dizzy," "relaxed," and "hungrier than usual" and NMDA-VAS ratings of "detached," "slow motion," and "unreal" $\left(F_{\mathrm{s}}[1,45]>4.35, p \mathrm{~s}<\right.$ 0.05; Table 3 and Fig. 1). All ratings increased significantly between baseline and presmoking measurements (paired $t \mathrm{~s}$ $[47]<-2.716, p s<0.01$ ), apart from the "relaxed" ratings, which tended to decrease (paired $t[47]=3.30, p<0.005$ ). In addition, a significant main effect of time point was observed for the QSU factor $2(F[1,45]=7.54, p<0.01$; Table 4), indicating that the negative reinforcement aspect of craving significantly increased across the two time points in all participants (paired $t[47]=-4.18, p<0.001$ ).

ANCOVA revealed a significant interaction of drug and time point for the Nic-VAS "stimulated" ratings $(\mathrm{F}[1,45]=5.82, p<0.05)$. Ratings for "stimulated" increased across time in the DCS group (paired $t[23]=$ $-2.823, p<0.01)$, while this was not observed in the PL group $(t[23]=0.36$, n.s.; Fig. 1a). All other subjective measures remained unaltered by DCS (drug $\times$ time interaction $F_{\mathrm{s}}[1,45]<1.78$, n.s.).

\section{Effects of DCS in combination with partial smoking (presmoke vs. postsmoke)}

Univariate ANCOVA of percent change from the presmoking time point was deemed necessary for Nic-VAS "buzzed," "jittery," and "dizzy" ratings, NMDA-VAS "lightheaded," "detached," and "slow motion," and QSU factor 2, since the analyses of the presmoking time point ratings for these dependent variables indicated a drug $\times$ condition interaction $(F \mathrm{~s}[1,42]>4.36, p \mathrm{~s}<0.05)$.

A significant interaction of drug group, partial-smoking condition, and time point was observed for the Nic-VAS "stimulated" and "relaxed" ratings (respectively, $F[1,42]=$ $7.50, p<0.01$ and $F[1,42]=5.18, p<0.05)$. Partial smoking induced an increase in "stimulated" and "relaxed" feelings 
in the PL group (respectively, paired $t[11]=-2.45, p<0.05$ and $t[11]=-2.48, p<0.05)$. In contrast, in the group given DCS, ratings for "stimulated" decreased significantly $(t[11]=2.44, p<0.05$; Figure $1 \mathrm{a})$, whereas ratings for "relaxed" remained the same after partial smoking compared with the presmoking time point $(t[11]=-0.27$, n.s.; Figure 1b).

In both treatment groups, partial smoking induced an increase in Nic-VAS "buzzed" ratings (\% change from presmoking time point, means \pm SEM: $S=175.87 \pm 55.28 \%$, $\mathrm{NS}=16.17 \pm 21.43 \%$; main effect of smoking $F[1,42]=4.32$, $p<0.05)$ and a decrease in QSU factor 2 scores ( $\%$ change from presmoking time point; main effect of smoking $F[1,42]=8.16, p<0.01$; see Table 4). In addition, a significant interaction of smoking group and time point was observed in the ANCOVA of QSU factor 1 scores $(F[1,42]=15.90, p<0.001$; Table 4$)$, and post hoc tests revealed that the scores declined after partial smoking $(t[23]=5.06, p<0.001)$ while they tended to remain unchanged in the nonsmoking group $(t[23]=-0.35$, n.s.). DCS did not modulate the effects of partial smoking either on the QSU ratings or on the subjective ratings of "buzzed" (main effect and interaction $F \mathrm{~s}[1,42]<1.93$, n.s.).

Cognitive effects

\section{Effects of DCS in combination with partial smoking (postsmoke measurement point)}

Neither partial smoking nor drug treatment altered the number of hits occurring during the RVIP test (means \pm SEM: $\mathrm{DCS} / \mathrm{NS}=22.8 \pm 2.5, \mathrm{DCS} / \mathrm{S}=25.9 \pm 2.2, \mathrm{PL} / \mathrm{NS}=$ $27.3 \pm 2.5, \mathrm{PL} / \mathrm{S}=23.4 \pm 2.6$; main effects and interaction $F \mathrm{~s}$ $[1,42]<0.91$, n.s.). However, a significant interaction of drug and partial-smoking condition was revealed for the number of false alarms $(F[1,41]=4.49, p<0.05$; Figure 2a). Partial smoking reduced the number of false alarms in the DCS group participants, who made significantly less errors than their nonsmoking counterparts $(t[12.91]=2.32$, $p<0.05)$ as well as less errors than the PL group participants who smoked $(t[12.29]=2.17, p=0.05)$. In addition, a significant main effect of drug group was observed for response latencies $(F[1,41]=6.43, p<0.05$; Fig. 2b) reflecting the tendency for the participants in the DCS group to have longer latencies than those in the PL group $(t[45]=-3.04, p<0.005)$. Partial smoking alone or in combination with DCS failed to exert a significant effect on response latencies (main effect and interaction $F \mathrm{~s}[1,41]$ $<2.95$, n.s.).

None of the aspects of IED test performance appeared to be influenced either by drug treatment or by partial smoking (main effects and interactions: $F_{\mathrm{s}}[1,42]<3.06$, $p \mathrm{~s}>0.08$ ) apart from the number of errors made in the first 
Table 3 Effects of D-cycloserine (DCS) and placebo (PL) on subjective ratings (nicotine-VAS and NMDA-VAS items) during nicotine abstinence

Measurements were taken at predrug baseline (t1), and 90 min after drug (t2). Values represent means $( \pm$ SEM)

${ }^{\#} p<0.05 ;{ }^{\# \#} p<0.01$ (main effect of time point; $\mathrm{t} 2$ vs. $\mathrm{t} 1)$

\begin{tabular}{|c|c|c|c|c|}
\hline \multirow[t]{2}{*}{$d f=1,45$} & \multicolumn{2}{|l|}{ DCS } & \multicolumn{2}{|l|}{ PL } \\
\hline & $\mathrm{t} 1$ & $\mathrm{t} 2$ & $\mathrm{t} 1$ & $\mathrm{t} 2$ \\
\hline \multicolumn{5}{|l|}{ Nicotine-VAS } \\
\hline "Buzzed"\#" & $19.3(4.1)$ & $34.1(6.3)$ & $22.6(4.0)$ & $30.6(5.3)$ \\
\hline "Impatient"\#" & $27.1(5.1)$ & $40.7(5.5)$ & $30.3(4.4)$ & $46.5(4.8)$ \\
\hline "Alert" & $44.0(5.1)$ & $46.1(5.5)$ & $46.2(4.6)$ & $50.0(4.5)$ \\
\hline "Irritable" & $24.5(4.9)$ & $27.1(5.3)$ & $31.2(4.6)$ & $42.0(5.6)$ \\
\hline "Jittery" & $21.6(4.8)$ & $25.5(5.5)$ & $29.8(4.4)$ & $34.5(4.9)$ \\
\hline "Dizzy"\# & $17.0(4.3)$ & $22.5(5.4)$ & $17.5(3.8)$ & $31.2(5.1)$ \\
\hline "Hungrier than usual"" & $31.2(6.4)$ & $38.3(6.5)$ & $30.8(5.9)$ & $49.3(6.7)$ \\
\hline \multicolumn{5}{|l|}{ NMDA-VAS } \\
\hline "Lightheaded" & $26.4(5.7)$ & $35.9(6.0)$ & $30.0(4.8)$ & $40.0(4.9)$ \\
\hline "Detached" " & $27.3(4.7)$ & $37.6(5.5)$ & $30.7(4.8)$ & $43.3(5.2)$ \\
\hline "Forgetful" & $32.5(4.5)$ & $42.4(5.6)$ & $38.9(4.9)$ & $38.7(5.6)$ \\
\hline "Slow motion"\#\# & $16.5(4.5)$ & $23.5(5.7)$ & $16.3(3.2)$ & $26.9(5.5)$ \\
\hline "Unreal"\# & $16.1(4.6)$ & $21.4(5.3)$ & $16.3(3.8)$ & $23.5(4.9)$ \\
\hline
\end{tabular}

two reversal blocks which tended to be reduced in the partial smoking compared to the abstinent condition (main effect of smoking condition; Block 2 errors: $F[1,42]=4.23$, $p<0.05$; Block 5 errors: $F[1,42]=4.02, p=0.052$; Table 5). A nonsignificant trend for partial smoking to improve IED performance was also observed in the analysis of total number of errors prior to the extradimensional shift block (main effect of smoking condition on Blocks 1-7; $F[1,42]=2.98, p=0.053)$. However, the analysis of this variable also revealed that duration of abstinence was a significant determinant of test performance $(F[1,42]=$ 12.38, $p<0.001)$, and post hoc correlational analysis indicated that longer abstinence was related to greater number of errors prior to the extradimensional shift (Pearson's $r=0.40, p<0.005$ ).

\section{Discussion}

The main findings from this study were that DCS, a partial agonist at the GlycineB site of the NMDA receptor, given alone had a mild stimulant effect in abstinent smokers and slowed reaction times somewhat, during a task of sustained attention. It reduced the subjective stimulant effect of partially smoking a cigarette and the accompanying increase in relaxation. In addition, DCS interacted with the effect of partial smoking to produce a small increase in blood pressure. While there was no interaction between DCS and partial smoking on attentional accuracy, there was an improvement in inhibitory control. These results fit well with those of our previous study using the NMDA antagonist memantine (Jackson et al. 2009) and which suggested a role for glutamate in subjective response to smoking, but not in the effects on attentional accuracy. Our current study also extends those results to reveal the role of glutamate in inhibitory control.

At the dose of $50 \mathrm{mg}$ DCS used in this study, we expected to see either "agonist-like" interactions or "antagonist-like" interactions with smoking (see "Introduction" section). A mild stimulant effect was detected using the Nic-VAS rating scales. Previous studies using this dose of DCS have not detected this subjective response in healthy volunteers (van Berckel et al. 1997; D'Souza et al. 2000; Bailey et al. 2007), although this is the first study to focus on a population of smokers. It seems unlikely that this reflects the antagonist property of DCS, as no effects were detected on the NMDA-VAS rating scales, which we have previously shown to be sensitive to the effects of the NMDA antagonist memantine (Jackson et al. 2009). It is more likely that the stimulant action represents an agonist property of DCS, and accordingly, this would imply that glutamate action at NMDA receptors is relatively low in smokers during early abstinence. Preclinical studies indicate that although the subjective effects of nicotine are partly mediated by the mesolimbic system, the primary site of action may be in the prefrontal cortex (Miyata et al. 2002; Smith and Stolerman 2009). Interestingly, NMDA receptors containing NR2B subunits, for which DCS has preferential affinity (Priestley et al. 1995), upregulate in the PFC as a consequence of chronic nicotine selfadministration (Wang et al. 2007). Such an upregulation could account for the stimulant-like effects of DCS seen in abstinent smokers in this study, an effect not seen in other studies employing healthy volunteers.

In addition to its effect on stimulant ratings per se during abstinence, DCS also interacted with the subjective effects 
a) 'Stimulated'

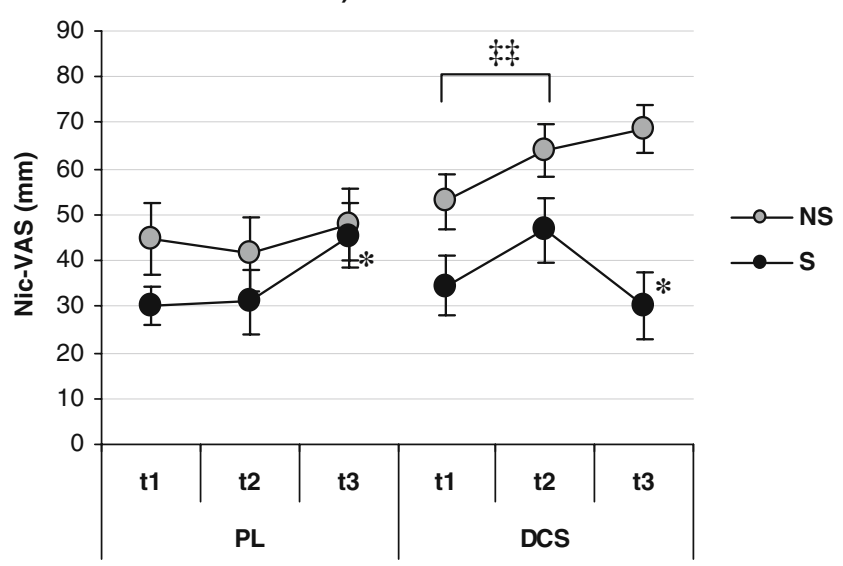

b) 'Relaxed'

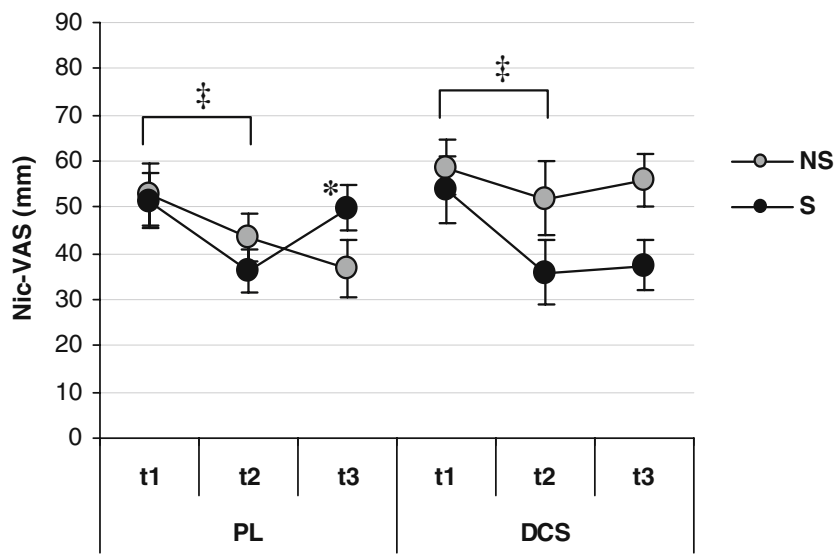

Fig. 1 Effects of drug $(D C S)$ or placebo $(P L)$ on Nic-VAS ratings of a "Stimulated" and b "Relaxed" at predrug baseline $(t 1)$, presmoking $(t 2)$, and postsmoking measurement point $(t 3)$. NS nonsmoking group, $S$ partial-smoking group (the two groups underwent identical protocol until the partial-smoking manipulation which occurred after t2). $₫ p<$ $0.05, \$+p<0.01$ (t1 vs. $\mathrm{t} 2$; paired $t$ test within DCS group), $* p<0.05$ (t2 vs. t3; paired $t$ test within PL-S and DCS-S groups) of partial smoking to reduce the increases seen in relaxed and stimulant ratings. This effect parallels results seen with NMDA antagonists in preclinical studies investigating the stimulus properties of nicotine (Zakharova et al. 2005; Murray and Bevins, 2007). The result is also consistent with our previous results showing modulation of smokinginduced subjective response using the Nic-VAS rating scales, although the modulated effects differed in that previously we found evidence for changes in ratings for "buzzed" (Jackson et al. 2009). One reason for this difference may be that in the current study, participants were asked to smoke only a portion of a cigarette, whereas previously, they smoked a whole cigarette, thus differential self-dosing produced a different profile of subjective effects. Different self-dosing is supported by comparison of the pre-postsmoking change in $\mathrm{CO}$ levels of the two studies (an average increase of $141.1 \%$ vs. $43.6 \%$ in the current study). Nevertheless, both studies provide evidence to support a role for glutamate release underlying subjective response to smoking. In addition, the "bidirectional action" of DCS on stimulant ratings depending on whether participants smoked or were abstinent fits well with the predicted action of DCS varying according to different levels of endogenous glutamate activity.

In contrast to the results obtained using the Nic-VAS rating scales, DCS did not alter craving measured by the QSU. Both factor 1 craving (positive reinforcement) and factor 2 craving (negative reinforcement) were reduced following the partial-smoking manipulation; DCS neither potentiated nor prevented this effect. Again, these results are consistent with those of our previous study with memantine (Jackson et al. 2009) and suggest that mechanisms other than glutamate activity at NMDA receptors may be involved in abstinence-related craving. Interestingly, our results differ from those of Santa Ana et al. (2009) where following repeated dosing with DCS, cue-induced (conditioned) craving was attenuated.

Table 4 QSU ratings of the two smoking groups ( $\mathrm{S}=$ partial-smoking condition, NS = nonsmoking condition) at predrug baseline ( $\mathrm{t} 1)$, before ( $\mathrm{t} 2)$, and after the partial-smoking manipulation ( $\mathrm{t} 3$ )

\begin{tabular}{|c|c|c|c|c|c|c|}
\hline & \multicolumn{3}{|c|}{ QSU factor 1 - positive reinforcement } & \multicolumn{3}{|c|}{ QSU factor 2 -negative reinforcement } \\
\hline & $\mathrm{t} 1$ & $\mathrm{t} 2$ & $\mathrm{t} 3 * * *$ & $\mathrm{t} 1$ & $\mathrm{t} 2^{\# \#}$ & $\mathrm{t} 3 * *$ \\
\hline DCS/NS & $5.3(0.4)$ & $5.7(0.4)$ & $5.6(0.4)$ & $3.2(0.5)$ & $3.9(0.6)$ & $3.6(0.6)$ \\
\hline $\mathrm{DCS} / \mathrm{S}$ & $5.5(0.3)$ & $5.4(0.4)$ & $4.1(0.4)$ & $2.8(0.2)$ & $2.9(0.4)$ & $2.0(0.3)$ \\
\hline $\mathrm{PL} / \mathrm{NS}$ & $5.3(0.4)$ & $5.6(0.4)$ & $5.7(0.4)$ & $2.6(0.3)$ & $2.8(0.3)$ & $3.1(0.5)$ \\
\hline $\mathrm{PL} / \mathrm{S}$ & $5.2(0.5)$ & $5.6(0.5)$ & $3.6(0.5)$ & $3.4(0.4)$ & $4.3(0.5)$ & $2.7(0.3)$ \\
\hline
\end{tabular}

The two groups underwent identical protocol until the partial-smoking manipulation, which occurred after t2. Values represent means $( \pm$ SEM), minimum score 1 , maximum 7

$* * * p<0.001$ (smoking group $\times$ time point interaction; $\mathrm{S}: \mathrm{t} 2<\mathrm{t} 3, \mathrm{~N}: \mathrm{t} 2=\mathrm{t} 3$ ) $; * * p<0.01$ (main effect of smoking group on the $\mathrm{t} 3$ scores expressed as $\%$ change from $\mathrm{t} 2$ ); ${ }^{\#} p<0.01$ (main effect of time point; $\mathrm{t} 2$ vs. $\mathrm{t} 1$ ) 
a) RVIP False alarms

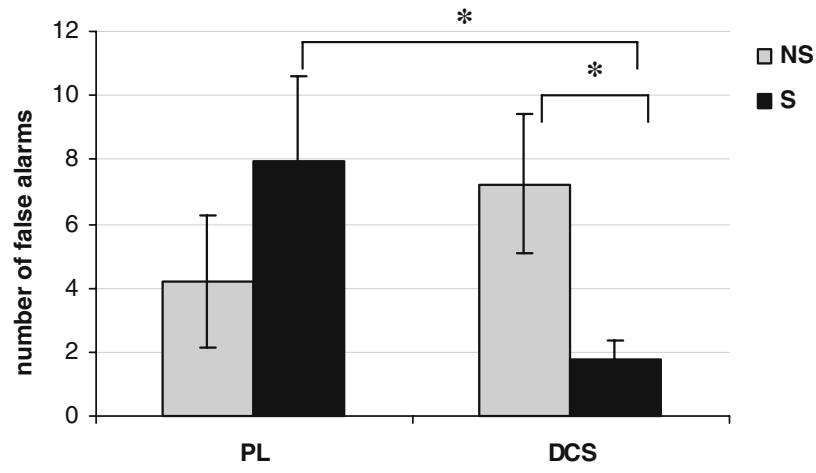

b) RVIP Mean RT

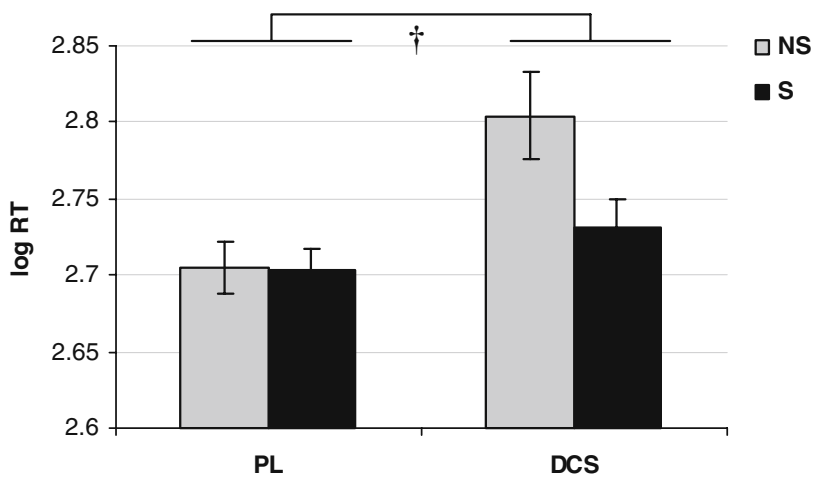

Fig. 2 a Number of false alarms and $\mathbf{b}$ mean response times $(\log )$ on the rapid visual information processing $(R V I P)$ test following partial smoking $(S)$ or the nonsmoking $(N S)$ manipulations in participants who underwent the drug $(D C S)$ or the placebo $(P L)$ treatment. ${ }^{*} p \leq$ 0.05 (independent $t$ test vs. DCS-S groups), $\uparrow p<0.05$ (main effect of drug group PL vs. DCS)
DCS lacked any effect on physiological measures, either alone or in combination with partial smoking, with one exception. While neither DCS alone nor smoking alone altered blood pressure, when in combination, a small increase in diastolic blood pressure was seen. Pressor responses seen after central administration of nicotinic agonists have been pharmacologically characterized and indicate that they are mediated via $\alpha 7$ homomeric nicotinic receptors (Brezenoff and Giuliano 1982; Buccafusco and Yang 1993; Li and Buccafusco 2004). As stimulation of $\alpha 7$ homomeric receptors can modulate glutamate release in several different areas of the brain (Kaiser and Wonnacott 2000; Schilstrom et al. 2000; Jones and Wonnacott 2004; Livingstone et al. 2009), a reasonable interpretation of our results is therefore that the increase in diastolic blood pressure seen following combined DCS and partial smoking was related to the agonist action of DCS potentiating the action of glutamate at central NMDA receptors. A candidate area in the brain for this action of DCS is the ventral portion of the medial prefrontal cortex-firstly because the prefrontal cortex contains both $\alpha 7$ nicotinic receptors (Paterson and Nordberg 2000) and NMDA receptors containing NR2B subunits (Laurie et al. 1997; Loftis and Janowsky 2003), and secondly, there is evidence for the involvement of glutamate in ventromedial prefrontal cortex provoked increases in blood pressure in unanesthetized rats (Resstel and Correa 2006).

DCS had no effect on the number of "hits" (target detections) achieved during performance of the RVIP test, either alone or in combination with partial smoking. Partial

Table 5 IED test performance of the four experimental groups (DCS = D-cycloserine condition, PL = placebo condition, $\mathrm{S}=$ partial-smoking condition, NS = nonsmoking condition)

\begin{tabular}{|c|c|c|c|c|}
\hline$n=12$ per group ( 6 male, 6 female) & DCS/NS & $\mathrm{DCS} / \mathrm{S}$ & $\mathrm{PL} / \mathrm{NS}$ & $\mathrm{PL} / \mathrm{S}$ \\
\hline Number of stages completed & $8.5(0.3)$ & $9.0(0.0)$ & $8.7(0.2)$ & $8.8(0.2)$ \\
\hline Total number of errors (adjusted for the stages not completed) & $24.6(6.3)$ & $12.4(2.2)$ & $20.6(4.7)$ & $17.3(4.2)$ \\
\hline Number of errors in stage 1 (discrimination learning) & $0.2(0.1)$ & $0.4(0.1)$ & $0.5(0.2)$ & $0.7(0.3)$ \\
\hline Number of errors in stage 2 (simple reversal learning)* & $1.7(0.2)$ & $1.3(0.1)$ & $1.5(0.3)$ & $1.2(0.1)$ \\
\hline Number of errors in stage 3 (new dimension introduced but ignored) & $2.3(1.8)$ & $1.2(0.2)$ & $2.7(1.0)$ & $1.0(0.2)$ \\
\hline Number of errors in stage 4 (new dimension still ignored) & $0.3(0.1)$ & $0.6(0.3)$ & $0.2(0.1)$ & $0.1(0.1)$ \\
\hline Number of errors in stage 5 (reversal, still ignoring the new dimension) ${ }^{\#}$ & $1.5(0.2)$ & $1.0(0.0)$ & $1.4(0.2)$ & $1.3(0.2)$ \\
\hline Number of errors in stage 6 (intradimensional set-shift) & $0.6(0.1)$ & $0.5(0.2)$ & $0.8(0.2)$ & $0.8(0.2)$ \\
\hline Number of errors in stage 7 (reversal, still ignoring the new dimension) & $1.3(0.2)$ & $1.1(0.1)$ & $1.4(0.3)$ & $1.2(0.1)$ \\
\hline Number of errors in stage 8 (extradimensional set-shift) & $9.5(3.3)$ & $4.9(2.4)$ & $6.2(2.4)$ & $7.3(2.6)$ \\
\hline Number of errors in stage 9 (reversal, still attending to the new dimension) & $1.3(0.2)^{\dagger \dagger \dagger}$ & $1.5(0.3)$ & $2.1(0.8)^{\dagger \dagger}$ & $1.8(0.2)^{\dagger}$ \\
\hline Total number of errors prior to extradimensional set-shift (blocks $1-7)^{\#}$ & $7.8(2.0)$ & $6.0(0.6)$ & $8.5(1.1)$ & $6.2(0.5)$ \\
\hline Reversal learning (errors in stages $2+5+7+9$ ) & $5.4(0.6)^{\dagger \dagger \dagger}$ & $4.8(0.3)$ & $6.5(0.9)^{\dagger \dagger}$ & $5.5(0.4)^{\dagger}$ \\
\hline Attentional flexibility (errors in stages $6+8$ ) & $10.1(3.3)$ & $5.4(2.3)$ & $7.0(2.4)$ & $8.2(2.6)$ \\
\hline
\end{tabular}

Test was performed after the smoking manipulation. Values represent means $( \pm \mathrm{SEM})$

${ }^{\dagger} n=11,{ }^{\dagger} n=10,{ }^{\dagger \dagger} n=9$

${ }^{*} p<0.05 ;{ }^{*} p<0.055$ (main effect of smoking group) 
smoking itself did not improve performance, although this might have been expected given the well-established effect of nicotine in this test (Wesnes and Warburton 1984). This lack of effect, however, is likely to stem from the fact that smoking half of the usual amount of tobacco is insufficient to produce the beneficial effect on attention. Indeed, Rezvani et al. (2002) observed that low doses of nicotine did not affect the number of "hits" in a visual signal detection test in rats even though they increased percent of correct rejections. However, under these conditions of low nicotine dosage, a beneficial effect of DCS in combination with partial smoking on the number of hits would likely have been detected, if this particular effect of smoking on sustained attention involves glutamate activity at NMDA receptors. There is some discrepancy with the preclinical literature in that one study investigating the beneficial action of nicotine in a 5-CSRTT found that the NMDA antagonist CPP was able to reduce the effect of nicotine on attentional accuracy (Quarta et al. 2007). It is possible then that had partial smoking improved attentional accuracy in our participants that DCS might have attenuated such an effect. However, our interpretation that glutamate action at NMDA receptors does not play a major role in this effect of smoking fits well with two other lines of evidence. Firstly, preclinical studies employing selective nicotinic ligands suggest that increases in attentional performance are primarily mediated by non- $\alpha 7$ receptor subtypes (Blondel et al. 2000; Grottick and Higgins 2000). Secondly, we previously found that the enhanced attentional accuracy in the RVIP test following smoking a whole cigarette was prevented by a low dose of mecamylamine but not by memantine (see Jackson et al. 2009 and discussion therein). Overall then, our results confirm that mechanisms underlying the positive attentional effects of smoking probably do not involve actions at NMDA receptors. There was some evidence that DCS slowed performance overall, during the task of sustained attention, as reaction times were increased. This effect however was independent of the partial-smoking manipulation. While this might suggest that DCS can affect response times, the lack of specific interaction makes it difficult to interpret in terms of a role for glutamate in the effects of smoking on speed of processing.

In contrast to the lack of specific effects on other measures of RVIP performance, DCS interacted with the partial-smoking manipulation to improve inhibitory control, as measured by the number of errors on the task. This result is in line with the observation that low doses of nicotine dose-dependently increase the percentage of correct rejections in a visual signal detection test in rats without affecting the number of hits (Rezvani et al. 2002). It is unlikely that the reduction in errors was secondary to slower reaction times as this effect only occurred when partial smoking and DCS were combined. In addition, the reduced error rate dissociated from target detection rate, which did not vary across the experimental conditions. Recently, it has been suggested that lapses in attention may contribute toward drug dependence via mechanisms that are independent of those involved in inhibitory control over behavior (De Wit, 2008). The results reported here are consistent with such a suggestion, at least in terms of a role for glutamate in tobacco dependence.

It is of interest to note here the wealth of evidence for the role of glutamate in inhibitory control. Administration of glutamate receptor antagonists such as phencyclidine, dizocilpine, or ketamine induces impulsive or premature responding for food rewards in rats (Sanger and Jackson 1989; Sanger 1992; Higgins et al. 2003) and primates (Jentsch et al. 2000) or impairs the inhibition of inappropriate responses during performance of cognitive tests in humans (Krystal et al. 1998; 1999; Morgan et al. 2004). Furthermore, NMDA antagonists that are selective for receptors containing the NR2B subunit (traxoprodil, Ro 63-1908) also increase premature responding in animal studies (Higgins et al. 2003; 2005). Finally, Murphy et al. (2005) showed that infusions of the competitive NMDA receptor antagonist CPP, into infralimbic (but not prelimbic) cortex increased premature responding in rats performing a 5CSRTT (this measure may be a parallel of RVIP error rate) and have consequently suggested that glutamatergic systems involved in response inhibition are localized to a ventromedial area of prefrontal cortex. In the light of a great deal of evidence indicating that antagonists at NMDA receptors impair inhibitory control, it is reasonable to conclude that the effect of DCS in combination with partial smoking reflects an agonist action, that is, a potentiation of the effect of glutamate, possibly mediated in the ventromedial prefrontal cortex.

There was no evidence that partial smoking affected performance on the attentional set-shifting task other than by reducing the number of reversal errors. Although we have previously seen smoking-induced impairment in the intradimensional set shift component of this task (Nesic et al. 2011), those results were obtained after smoking a whole cigarette, so it is probable that the lack of effect in the present study was due to the self-administration of a subthreshold dose of nicotine. Set shifting was also unaltered by DCS alone, or the combination with partial smoking. So, while ligands acting at NMDA receptors have been shown to alter perseverative responding in tests of cognitive flexibility in other populations (Krystal et al. 1998; Heresco-Levy et al. 2002), we were unable to detect an effect of DCS in smokers, nor did we see any potentiation of partial smoking. Given the ability of DCS to potentiate the effects of limited smoking on other measures (blood pressure, inhibitory control), this once again emphasizes the dissociation in mechanisms underlying the different cognitive actions of nicotine.

An important issue, which complicates the interpretation of the present findings, is the baseline difference in the duration of 
smoking abstinence between the two drug groups. Analysis of covariance was used to try to control for this confounding effect as well as for the confounding effect of the differential level of breath $\mathrm{CO}$ at baseline (reflecting abstinence duration as well as the habitual level of smoking) in the two smoking groups, but this may not have been sufficient. This issue is also pertinent considering that the state of glutamatergic transmission may vary depending on the degree of dependence and the duration of smoking deprivation (see Markou 2008 for a review), and thus the effects of DCS and/or partial smoking may differ between individuals in early, compared to those in more advanced, nicotine withdrawal. Furthermore, as the mode of action of DCS depends on the dose (Priestley et al. 1995) as well as on endogenous glutamatergic tone (Jackson 2010), a study, which would systematically vary the doses of DCS as well as of nicotine, while controlling for the duration of abstinence, is needed to produce dose-response data which would give more detailed insight into the involvement of NMDA receptor activation in the subjective and cognitive effects of smoking. Another problem with the present study is the relatively small sample size. Although the sample of 12 per group was selected because it has relatively high power $(0.80)$ to detect medium-sized effects $(\alpha=0.25)$, the inclusion of the covariates in the analyses has reduced this power. Future studies with a larger number of participants are needed to confirm the significance of the present findings.

In summary, the glycine-site partial agonist DCS had bidirectional effects on subjective ratings in moderately dependent smokers, depending on whether they were abstinent or had partially smoked a cigarette. In combination with partial smoking, DCS produced a small increase in blood pressure and improved inhibitory control, but did not affect attentional accuracy or set shifting. These results are consistent with a role for glutamate in the some of the subjective and physiological effects of smoking and with a dissociation in mechanisms underlying the cognitive actions. Considered in the context of current knowledge about relevant brain mechanisms, our results point to the actions of DCS being mediated in the ventromedial prefrontal cortex.

Acknowledgments This work was funded by the Wellcome Trust (grant number 074354).

Open Access This article is distributed under the terms of the Creative Commons Attribution Noncommercial License which permits any noncommercial use, distribution, and reproduction in any medium, provided the original author(s) and source are credited.

\section{References}

Bailey JE, Papdopoulos A, Lingford-Hughes A, Nutt DJ (2007) DCycloserine and performance under different states of anxiety in healthy volunteers. Psychopharmacology 193:579-585
Blokhina EA, Kashkin VA, Zvartau EE, Danysz W, Bespalov AY (2005) Effects of nicotinic and NMDA receptor channel blockers on intravenous cocaine and nicotine self-administration in mice. Eur Neuropsychopharmacol 15:219-225

Blondel A, Sanger DJ, Moser PC (2000) Characterisation of the effects of nicotine in the five-choice serial reaction time task in rats: antagonist studies. Psychopharmacology 149:293-305

Brezenoff HE, Giuliano R (1982) Cardiovascular control by cholinergic mechanisms in the central nervous system. Annu Rev Pharmacol Toxicol 22:341-381

Buccafusco JJ, Yang XH (1993) Mechanism of the hypertensive response to central injection of nicotine in conscious rats. Brain Res Bull 32:35-41

Ciamei A, Aversano M, Cestari V, Castellano C (2001) Effects of MK801 and nicotine combinations on memory consolidation in CD1 mice. Psychopharmacology 154:126-130

Cox LS, Tiffany ST, Christen AG (2001) Evaluation of the brief questionnaire of smoking urges (QSU-brief) in laboratory and clinical settings. Nicotine Tob Res 3:7-16

Danysz W, Parsons CG (1998) Glycine and NMDA receptors: physiological significance and possible therapeutic applications. Pharmacol Rev 50:597-664

De Wit H (2008) Impulsivity as a determinant and consequence of drug use: a review of underlying processes. Addict Biol 14:2231

D'Souza DC, Gil R, Cassello K, Morrissey K, Abi-Saab D, White J, Sturwold R, Bennett A, Karper LP, Zuzarte E, Charney DS, Krystal JH (2000) IV glycine and oral D-cycloserine effects on plasma and CSF amino acids in healthy humans. Biol Psychiatry 47:450-462

Fagen ZM, Mansvelder HD, Keath JR, McGehee DS (2003) Shortand long-term modulation of synaptic inputs to brain reward areas by nicotine. Ann NY Acad Sci 1003:185-195

Fagerström KO (1978) Measuring degree of physical dependence to tobacco smoking with reference to individualization of treatment. Addict Behav 3:235-241

Fu Y, Matta SG, Gao W, Brower VG, Sharp BM (2000) Systemic nicotine stimulates dopamine release in nucleus accumbens: reevaluation of the role of N-methyl-D-aspartate receptors in the ventral tegmental area. J Pharmacol Exp Ther 294:458-465

Gioanni Y, Rougeot C, Clarke PB, Lepouse C, Thierry AM, Vidal C (1999) Nicotinic receptors in the rat prefrontal cortex: increase in glutamate release and facilitation of mediodorsal thalamocortical transmission. Eur J Neurosci 11:18-30

Glick SD, Maisonneuve IM, Dickinson HA, Kitchen BA (2001) Comparative effects of dextromethorphan and dextrorphan on morphine, metamphetamine and nicotine self-administration in rats. Eur J Pharmacol 422:87-90

Gray R, Rajan AS, Radcliffe KA, Yakehiro M, Dani JA (1996) Hippocampal synaptic transmission enhanced by low concentrations of nicotine. Nature 383:713-716

Grottick AJ, Higgins GA (2000) Effect of subtype selective nicotinic compounds on attention as assessed by the five-choice serial reaction time task. Behav Brain Res 117:197-208

Haradahira T, Okauchi T, Maeda J, Zhang MR, Nishikawa T, Konn Suzuki K, Suhara T (2003) Effects of endogenous agonists, glycine and D-serine, on in vivo specific binding of [11C]L-703, 717, a PET radioligand for the glycine-binding site of NMDA receptors. Synapse 50:130-136

Heresco-Levy U, Kremer I, Javitt DC, Goichman R, Reshef A, Blanaru M, Cohen T (2002) Pilot-controlled trial of Dcycloserine for the treatment of post-traumatic stress disorder. Int J Neuropsychopharmacol 5:301-307

Higgins GA, Ballard TM, Huwyler J, Kemp JA, Gill R (2003) Evaluation of the NR2B-selective NMDA receptor antagonist Ro 63-1908 on rodent behaviour: evidence for an involvement of 
NR2B receptors in response inhibition. Neuropharmacology 44:324-341

Higgins GA, Ballard TM, Enderlin M, Haman M, Kemp JA (2005) Evidence for improved performance in cognitive tasks following selective NR2B NMDA receptor antagonist pre-treatment in the rat. Psychopharmacology 179:85-98

Hofmann SG, Meuret AE, Smits JAJ, Simon NM, Pollack MH, Eisenmenger K, Shiekh M, Otto MW (2006) Augmentation of exposure therapy with D-cycloserine for social anxiety disorder. Arch Gen Psychiatry 63:298-304

Hood WF, Compton RP, Monahan JB (1989) D-cycloserine: a ligand for the N-methyl-D-aspartate coupled glycine receptor has partial agonist characteristics. Neurosci Lett 98:91-95

Jackson A (2010). Cognitive enhancers: role of the glutamate system. In: Encyclopedia of Psychopharmacology. Part 3, pp 317-322. Ed: Stolerman IP. Springer

Jackson A, Nesic J, Groombridge C, Clowry O, Rusted J, Duka T (2009) Differential involvement of glutamatergic mechanisms in the cognitive and subjective effects of smoking. Neuropsychopharmacology 34:257-265

Jentsch JD, Roth RH, Taylor JR (2000) Object retrieval/detour deficits in monkeys produced by prior subchronic phencyclidine administration: evidence for cognitive impulsivity. Biol Psychiatry 48:415-424

Jones IW, Wonnacott S (2004) Precise localization of $\alpha 7$ nicotinic acetylcholine receptors on glutamatergic axon terminals in the rat ventral tegmental area. J Neurosci 24:11244-11252

Kaiser S, Wonnacott S (2000) Alpha-bungarotoxin-sensitive nicotinic receptors indirectly modulate $[3 \mathrm{H}]$ dopamine release in rat striatal slices via glutamate release. Mol Pharmacol 58:312-318

Kenny PJ, Chartoff E, Roberto M, Carlezon WA Jr, Markou A (2009) NMDA receptors regulate nicotine-enhanced brain reward function and intravenous nicotine self-administration: role of the ventral tegmental area and central nucleus of the amygdale. Neuropsychopharmacology 34:266-281

Knott V, McIntosh J, Millar A, Fisher D, Villeneuve C, Ilivitsky V, Horn E (2006) Nicotine and smoker status moderate brain electric and mood activation induced by ketamine, an $\mathrm{N}$ methyl-D-aspartate (NMDA) receptor antagonist. Pharmacol Biochem Behav 85:228-242

Krystal JH, D'Souza DC, Karper LP, Bennett A, Abi-Dargham A, Abi-Saab D, Cassello K, Bowers MB, Vegso S, Heninger GR, Charney DS (1999) Interactive effects of subanesthetic ketamine and haloperidol in healthy humans. Psychopharmacology 145:193-204

Krystal JH, Karper LP, Bennett A, D'Souza DC, Abi-Dargham A, Morrissey K, Abi-Saab D, Bremner JD, Bowers MB, Suckow RF, Stetson P, Heninger GR, Charney DS (1998) Interactive effects of subanesthetic ketamine and subhypnotic lorazepam in humans. Psychopharmacology 135:213-229

Laurie DJ, Bartke I, Schoepfer R, Naujoks K, Seeburg PH (1997) Regional, developmental and interspecies expression of the four NMDAR2 subunits, examined using monoclonal antibodies. Mol Brain Res 51:23-32

Levin ED, Bettegowda C, Weaver T, Christopher NC (1998) Nicotinedizocilpine interactions and working and reference memory performance of rats in the radial-arm maze. Pharmacol Biochem Behav 61:335-340

Levin ED, McClernon FJ, Rezvani AH (2006) Nicotine effects on cognitive function: behavioural characterization, pharmacological specification and anatomic localization. Psychopharmacology 184:523-539

Li XD, Buccafusco JJ (2004) Role of $\alpha 7$ nicotinic acetylcholine receptors in the pressor response to intracerebroventricular injection of choline: blockade by amyloid peptide A $\beta 1-42$. J Pharmacol Exp Ther 309:1206-1212
Livingstone PD, Srinivasan J, Kew JNC, Dawson LA, Gotti C, Moretti M, Shoaib M, Wonnacott S (2009) $\alpha 7$ and non- $\alpha 7$ nicotinic acetylcholine receptors modulate dopamine release in vitro and in vivo in the rat prefrontal cortex. Eur $\mathrm{J}$ Neurosci 29:539-550

Loftis JM, Janowsky A (2003) The N-methyl-D-aspartate receptor subunit NR2B: localization, functional properties, regulation, and clinical implications. Pharmacol Ther 97:55-85

Mansvelder HD, McGehee DS (2000) Long-term potentiation of excitatory inputs to brain reward areas by nicotine. Neuron 27:349-357

Markou A (2008) Review. Neurobiology of nicotine dependence. Philos Trans R Soc Lond B Biol Sci 363:3159-3168

May-Simera H, Levin ED (2003) NMDA systems in the amygdala and piriform cortex and nicotinic effects on memory function. Cog Brain Res 17:475-483

McGehee DS, Heath MJS, Gelber S, Devay P, Role LW (1995) Nicotine enhancement of fast excitatory synaptic transmission in CNS by presynaptic receptors. Science 269:1692-1696

Mehrabian A, Russell JA (1978) A questionnaire measure of habitual alcohol use. Psychol Rep 43:803-806

Millan MJ (2005) N-Methyl-D-aspartate receptors as a target for improved antipsychotic agents: novel insights and clinical perspectives. Psychopharmacology 179:30-53

Miyata H, Ando K, Yanagita T (2002) Brain regions mediating the discriminative stimulus effects of nicotine in rats. Ann NY Acad Sci 965:354-363

Morgan CJA, Mofeez A, Brandner B, Bromley L, Curran HV (2004) Ketamine impairs response inhibition and is positively reinforcing in healthy volunteers: a dose-response study. Psychopharmacology 172:298-308

Murphy ER, Dalley JW, Robbins TW (2005) Local glutamate receptor antagonism in the rat prefrontal cortex disrupts response inhibition in a visuospatial attentional task. Psychopharmacology 179:99-107

Murray JE, Bevins RA (2007) Behavioral and neuropharmacological characterization of nicotine as a conditional stimulus. Eur $\mathrm{J}$ Pharmacol 561:91-104

Nesic J, Duka T (2006) Gender specific effects of a mild stressor on alcohol cue reactivity in heavy social drinkers. Pharmacol Biochem Behav 83:239-248

Nesic J, Duka T (2008) Effects of stress on emotional reactivity in hostile heavy social drinkers following dietary tryptophan enhancement. Alcohol Alcohol 43:151-162

Nesic J, Duka T, Rusted J, Jackson A (2008) Effects of the glycinesite partial agonist d-cycloserine on the cognitive and subjective effects of smoking. J Psychopharm 22:A69

Nesic J, Rusted J, Duka T, Jackson A (2011) Degree of dependence influences the effect of smoking on cognitive flexibility. Pharm Biochem Behav (in press)

Parsons CG, Danysz W, Quack G (1999) Memantine is a clinically well tolerated N-methyl-D-aspartate (NMDA) receptor antagonist - a review of preclinical data. Neuropharmacology 38:735-767

Parsons CG, StÖffler A, Wojciech Danysz W (2007) Memantine: a NMDA receptor antagonist that improves memory by restoration of homeostasis in the glutamatergic system - too little activation is bad, too much is even worse. Neuropharmacology 53:699-723

Paterson D, Nordberg A (2000) Neuronal nicotinic receptors in the human brain. Prog Neurobiol 61:75-111

Paterson NE, Markou A (2005) The metabotropic glutamate receptor 5 antagonist MPEP decreased break points for nicotine, cocaine and food in rats. Psychopharmacology 179:255-261

Paterson NE, Semenova S, Gasparini F, Markou A (2003) The mGluR5 antagonist MPEP decreased nicotine self-administration in rats and mice. Psychopharmacology 167:257-264 
Perkins KA, Sanders M, Fonte C, Wilson AS, White W, Stiller R, McNamara D (1999) Effects of central and peripheral nicotinic blockade on human nicotine discrimination. Psychopharmacology 142:158-164

Priestley T, Laughton P, Myers J, Le Bourdelles B, Kerby J, Whiting PJ (1995) Pharmacological properties of recombinant human Nmethyl-D-aspartate receptors comprising NR1a/NR2A and NR1a/NR2B subunit assemblies expressed in permanently transfected mouse fibroblast cells. Mol Pharmacol 48:841-848

Quarta D, Naylor CG, Morris HV, Patel S, Genn RF, Stolerman IP (2007) Different effects of ionotropic and metabotropic glutamate receptor antagonists on attention and the attentional properties of nicotine. Neuropharmacology 53:421-430

Radcliffe KA, Fisher JL, Gray R, Dani JA (1999) Nicotine modulation of glutamate and GABA synaptic transmission of hippocampal neurons. Ann NY Acad Sci 868:591-610

Reid MS, Fox L, Ho LB, Berger SP (2000) Nicotine stimulation of extracellular glutamate levels in the nucleus accumbens: neuropharmacological characterization. Synapse 35:129-136

Ressler KJ, Rothbaum BO, Tannenbaum L, Anderson P, Graap K, Zimand E, Hodges L, Davis M (2004) Cognitive enhancers as adjuncts to psychotherapy: use of D-cycloserine in phobic individuals to facilitate extinction of fear. Arch Gen Psychiatry 61:1136-1144

Resstel LBM, Correa FMA (2006) Involvement of the medial prefrontal cortex in central cardiovascular modulation in the rat. Auton Neurosci Basic Clin 126-127:130-138

Rezvani AH, Bushnell PJ, Levin ED (2002) Effects of nicotine and mecamylamine on choice accuracy in an operant visual signal detection task in female rats. Psychopharmacology 164:36-375

Rezvani AH, Levin ED (2003) Nicotinic-glutamatergic interactions and attentional performance on an operant visual signal detection task in female rats. Eur J Pharmacol 465:83-90

Riekkinen M, Riekkinen P (1997) Nicotine and D-cycloserine enhance acquisition of water maze spatial navigation in aged rats. NeuroReport 8:699-703

Roberts MJ, Russo R (1999) A student's guide to analysis of variance. Routledge, London

Rusted JM, Graupner L, Tennant A, Warburton DM (1998) Effortful processing is a requirement for nicotine-induced improvements in memory. Psychopharmacology 138:362-368

Rusted JM, Trawley S, Heath J, Kettle G, Walker H (2005) Nicotine improves memory for delayed intentions. Psychopharmacology 182:355-365

Sanger DJ (1992) NMDA antagonists disrupt timing behaviour in rats. Behav Pharmacol 3:593-600
Sanger DJ, Jackson A (1989) Effects of phencyclidine and other Nmethyl-D-aspartate antagonists on the schedule-controlled behavior of rats. J Pharmacol Exp Ther 248:1215-1221

Santa Ana EJ, Rounsaville BJ, Frankforter TL, Nich C, Babuscio T, Poling J, Gonsai K, Hill KP, Carroll KM (2009) D-Cycloserine attenuates reactivity to smoking cues in nicotine dependent smokers: a pilot investigation. Drug Alcohol Depend 104:220-227

Schilstrom B, Nomikos GG, Nisell M, Hertel P, Svensson TH (1998) Nmethyl-D-aspartate receptor antagonism in the ventral tegmental area diminishes the systemic nicotine-induced dopamine release in the nucleus accumbens. Neuroscience 82:781-789

Schilstrom B, Fagerquist MV, Zhang X, Hertel P, Panagis G, Nomikos GG, Svensson TH (2000) Putative role of presynaptic $\alpha 7$ nicotinic receptors in nicotine stimulated increases of extracellular levels of glutamate and aspartate in the ventral tegmental area. Synapse 38:375-383

Stolerman IP, Jarvis MJ (1995) The scientific case that nicotine is addictive. Psychopharmacology 117:2-10

Smith JW, Stolerman IP (2009) Recognising nicotine: the neurobiological basis of nicotine discrimination. Handb Exp Pharmacol 192:295-333

Toth E, Vizi ES, Lajitha A (1993) Effect of nicotine on levels of extracellular amino acids in regions of the rat brain in vivo. Neuropharmacology 32:827-832

Van Berckel BNM, Lipsch C, Timp S, Gispen-de Wied C, Wynne H, van Ree JM, Kahn RS (1997) Behavioral and neuroendocrine effects of the partial NMDA agonist D-cycloserine in healthy subjects. Neuropsychopharmacology 16:317-324

Wang F, Chen H, Steketee JD, Sharp BM (2007) Upregulation of ionotropic glutamate receptor subunits within specific mesocorticolimbic regions during chronic nicotine self-administration. Neuropsychopharmacology 32:103-109

Watkins SS, Koob GF, Markou A (2000) Neural mechanisms underlying nicotine addiction: acute positive reinforcement and withdrawal. Nic Tob Res 2:19-37

Wesnes K, Warburton DM (1984) Effects of scoplolamine and nicotine on human rapid visual information processing performance. Psychopharmacology 82:147-150

Wright JM, Vann RE, Gamage TF, Damaj MI, Wiley JL (2006) Comparative effects of dextromethorphan and dextrorphan on nicotine discrimination in rats. Pharmacol Biochem Behav 85:507-513

Zakharova ES, Danysz W, Bespalov AY (2005) Drug discrimination analysis of NMDA receptor channel blockers as nicotinic receptor antagonists in rats. Psychopharmacology 179:128-135 